\title{
TRENDS IN THE TRAINING OF IT SPECIALISTS: EXPERIENCE OF INTERUNIVERSITY COOPERATION
}

\author{
Iveta Mietule \\ Rezekne Academy of Technologies, Latvia \\ Aksana Holubeva \\ Polotsk State University, Republic of Belarus \\ Inha Ziankova \\ Polotsk State University, Republic of Belarus \\ Alena Lisichonak \\ Polotsk State University, Republic of Belarus
}

\begin{abstract}
The active development of information technology determines the need to ensure the supply-demand balance of labour in the labour market. In modern conditions, it is necessary not only to increase the output of specialists with IT knowledge and skills, but also to orient all students, regardless of specialty, to receive other flexible digital skills. The main aim of the research study is to justify the need for the priority development of IT specialties and flexible digital skills in higher educational institutions, to identify its main trends at Polotsk State University, in the framework of cooperation with Rezekne Academy of Technologies, in particular. The research methodology is based on the principles of system analysis, formal logic and an interdisciplinary scientific approach. The novelty of the research is to generalize the unique experience of training specialists at the Faculty of Information Technology of Polotsk State University, based on the practical orientation of the learning process. In addition, the paper provides information characterizing the development trends of the IT sector in Belarus. The following recommendations are proposed:

1) the implementation of the principle of building up cross-functional skills by students at the first stage of higher education, and then this is a deep specialization of the workforce throughout life;

2) the use of creative educational technologies;

3) the creation of a web tool that implements the task of creating flexible digital skills among the population of older working age and children through training in the Republic of Latvia and the Republic of Belarus;

4) the implementation of joint educational programmes with a double diploma.
\end{abstract}

Keywords: digital economy, digital skills, flexible skills, information technology IT-education; IT sphere. 
Mietule et al., 2020. Trends in the Training of IT Specialists: Experience of Interuniversity Cooperation

\section{Introduction}

Information technology is becoming an integral part of the development of modern socio-economic relations. The «informational dependence» of all stages of social reproduction is growing on the availability and accessibility of relevant, reliable information and the means to obtain and use it (Zaitseva, 2016).

Information technologies are the basis for improving the country's intellectual resources, which are necessary to provide additional potential for economic growth. Internet technologies that provide opportunities to improve the quality of work and the competence of subjects of the labour market occupy a special place in this process (Avdeeva \& Chaplygina, 2017).

The nature of the development of information technologies is due to a combination of global and local trends. These include the global strategy for the transition to the information society (WSIS), the main directions for the implementation of the Eurasian Economic Union digital agenda until 2025, the State Programme for the Development of the Digital Economy and Information Society for 2016-2020, the Strategy «Science and Technology: 2018-2040», the National Strategy for Sustainable Development of Belarus for the period until 2035 (draft).

All this determines the need for training high-level specialists in the field of IT-technologies.

The main aim of the research study is to justify the need for the priority development of IT specialties and flexible digital skills in higher educational institutions, to identify its main trends at Polotsk State University, in the framework of cooperation with Rezekne Academy of Technologies, in particular. The research methodology is based on the principles of system analysis, formal logic and an interdisciplinary scientific approach.

\section{Theory and practice of the formation of demand and supply in the labour market by specialties and education profiles}

An analysis of theoretical approaches to rational employment (Ziankova, 2019) made it possible to generalize the reasons for the insufficient implementation of the principle of the maximum value of the workforce at workplaces on the national and international labour market.

The issue of matching skills remains relevant, as well as the related issue of insufficient and excessive continuing education. According to Eurofound research (Eurofound, 2016), in 28 countries of the European Union in 2005 2015, $14 \%$ of the total employed population was classified as «underqualified», and $28 \%$ - had the status of «over-qualified». 
So, in 2015, the share of insufficiently qualified workers varied from 6 to 30 percent, and the share of retrained workers ranged from 16 to 40 percent. For example, France and Sweden were the countries that showed the largest increase in the share of unskilled workers in 2005 - 2015 (from 10 to 19 percent in France, from 6 to 15 percent in Sweden), while in Greece and Turkey there was a decrease in this category of employed population. For the same period, France showed the largest decline in the employed population in the status of «superskilled» from 46 to 26 percent, and Croatia - from 43 to 29 percent. Observations on the expectations of workers of their ability to work are interesting. For example, more than $80 \%$ of male and female workers under the age of 55 in Germany, Portugal, Denmark, Sweden believe that they can work up to 60 years.

In Denmark, the Netherlands, Norway, Sweden, workers are ready to finish work at 67 years old, and in Albania, Greece, Hungary, Malta, Slovakia, Turkey, workers are ready to finish work at 62 years old (Eurofound, 2016).

The authors also revealed that the principle of building students crossfunctional skills at the first stage of higher education, and then - deep specialization of the workforce throughout life is not fully implemented (The Global Human Capital Report, 2017).

At the Economic Forum in Davos (Economic forum in Davos, 2019), global risks associated with unemployment, as well as underemployment as a fact of the underutilized production potential of the employed population, which are aggravated by the adverse effects of technological advances, and the aging trend of society, are discussed.

A study of global documents (The Global Human Capital Report, 2017) showed that in the world community, national labour markets show a different demand for labour across specialties. For example, business administration and law, social sciences, information and communication technologies are the most popular specializations in all labour markets. The economies of South America (Argentina, Brazil, Chile and Colombia) are characterized by the employment of specialists in business, administration and law, while students in Ireland, Denmark, the United States, Canada, New Zealand and France specialize more in arts and human sciences.

Technical specialties and construction are required by the economies with a high demand for petrochemical engineers such as Qatar, Brunei Darussalam, Kuwait, the United Arab Emirates, Malaysia and Bahrain.

In Belarus, the graduation of specialists from higher education institutions, which forms the labour supply in 2018, was represented by the following main education profiles (National Statistical Committee of the Republic of Belarus, 2019): communications, law, economy, management, economics and organization of production - 36.3 percent of total output; engineering and 
Mietule et al., 2020. Trends in the Training of IT Specialists: Experience of Interuniversity Cooperation

technology - 12.2 percent (it is this type of education that specializes in the ITsphere); pedagogy - 9.5 percent; agriculture and forestry, landscape gardening 7.5 percent.

About 70 thousand specialists work in the information and communication technologies sector (millions in other fields of the economy), but despite their small numbers, it was this field in Belarus that determined the dynamics of the key economic indicator, gross domestic product, in 2019. In January-August, the growth of gross domestic product amounted to 1.1 percent. At the same time, the contribution of information and communication technology sector organizations was 0.55 percentage points. The same contribution to the growth of gross domestic product was made by all the organizations related to other fields industry, construction, agriculture, forestry, fisheries and trade. Thus, the contribution to the growth of the gross domestic product of one specialist in the field of information and communication technologies was on average 54 times greater than the contribution of one specialist in another field. However, the high growth rates of export earnings of residents of the high-tech park were more impressive.

In the first half of 2019, the export of high-tech park residents' services increased by 38.1 percent (National Statistical Committee of the Republic of Belarus, 2019).

In Western countries, there is an active process of digitalization of the economy. Developed countries are willing to spend tens of billions of dollars to finance this process. Accordingly, the demand for programmers, engineers, and other IT specialists is high, and thanks to this, the export of computer services in Belarus is growing by tens of percent annually. As for the prospects of the IT sector, for high growth rates of this industry, education in the field of high technologies should be actively developed.

In the past five years, a steady trend has been formed in Polotsk, Novopolotsk, Vitebsk. This is the creation of new IT companies and the opening of branches of large Belarusian and foreign IT companies Corpitech, AndersenBel, A1QA, ITechArt, Ocsico, SaM Solutions, FuryLion (almost 1000 new job vacancies for industrial programmers were created in Polotsk, Novopolotsk), LACIT, Epam Systems, Exadel, ITS Partner, ITechArt Andersen-Bel etc. (Vitebsk). In fact, a stable system of three complementary components has developed in the Polotsk region: high-quality physics and mathematics education in schools, competitive IT education in Polotsk State University, and innovative high-capacity entrepreneurship.

Investing in the development of IT education and the sector of information and communication technologies in the regions, the state solves the problem of the outflow of young talented specialists to Minsk or abroad. 
Analysing the increasing number of distributed graduates of the Faculty of Information Technology of Polotsk State University (from 24 in 2012 to 112 in 2019), a growing number (from 200 people in 2008 to 1,100 in 2019), as well as an expanding line of specialties (from 2 in 2008 to 5 in 2020), we observe a stable state support of training at the Faculty of Information Technology. This is due to the high quality of education, which allows one to employ all the graduates of the state-funded education. This will ensure the competitiveness of Belarus in the global economy and the sustainable growth of its gross domestic product.

\section{Experience of the Faculty of Information Technology of Polotsk State University in the training of IT specialists, taking into account the changing requirements of the labour market}

The All-Russian Centre for the Study of Public Opinion conducted a largescale study of the attitude of the Russian society towards higher education, during which about 30 questions were asked (All-Russian Centre for the Study of Public Opinion, 2019).

First question: «People want to get a higher education. What do you think, why?»

Of the nine motives for obtaining a higher education proposed, the respondents put the following motive in first place - «getting a diploma to get a good job» (33\%), and second - «getting specialized knowledge in order to become a good professional» (25\%).

Polotsk State University conducted a similar research study among 300 respondents.

According to the study, the answer «obtaining a diploma to get a good job» took first place (42 percent), the answer «obtaining special knowledge to be a good professional» took second place (30 percent).

The second question: «Which of the opinions on higher education do you most agree with?»

Sixty four percent of the Russian respondents and 66 percent of the Belarusian respondents chose the following answer option: «Higher education, first of all, should provide special professional knowledge and skills in the field chosen by a student, so that, after graduating from high school, s/he can easily move from theory to practice». The answer «Higher education should provide general knowledge and skills, provide a broad outlook so that a student can study independently in the future, to cover new areas of knowledge» was chosen by 28 percent of the Russian and 34 percent of the Belarusian respondents.

The third question: «What, in your opinion, is the most important during your studies?» 
Mietule et al., 2020. Trends in the Training of IT Specialists: Experience of Interuniversity Cooperation

Of the eight proposed answers, no more than two could be chosen. The respondents from Russia put the answer «It's good to study, to make the best possible professional in one's field» in first place (59 percent), in second place «To find a future job, establish contacts with potential employers» (34 percent).

The Belarusian respondents preferred the answers «To learn to live independently, acquire skills of adult behaviour, be responsible for oneself» (28 percent) and «To study well, to make the best possible professional in one's field» (25 percent).

The results of the questionnaires lead us to the conclusion that it is important to quickly build skills in labour resources, taking into account the changing conditions of the labour market.

Despite the fact that there are three or four resumes per vacancy in the IT sector, the information technology sector is experiencing a shortage of specialists.

Experienced professionals are rarely in an active job search and they are not represented on job sites. IT companies are forced to lure them from each other through interesting projects and higher salaries. The graduates of IT specialties of universities have insufficient knowledge for a quick start. In addition, there are areas that have arisen recently, so there are no ready-made personnel for them (serverless computing, blockchain technology, data mining, pentesting, DevOps and much more). The situation is complicated by the fact that due to the development of digital technologies, the requirements for employees continue to increase. All this complicates the development of the IT industry and forces companies to spend resources on training and fighting for employees, and not on production.

However, despite the increasing requirements for work skills, there are criteria that remain virtually unchanged for today's scarce developers. These are: work experience of two years (preferably in large projects), knowledge of tools and frameworks used by the customer, conversational English (Intermediate level), technical English, higher IT education.

To develop special professional skills, attract young staff who dream of working in a specific IT company, reduce the period of the adaptation period, leading IT company experts conduct specialized free courses for students of the Faculty of Information Technology. This undoubtedly contributes to the successful distribution of graduates («Java Programming» - LACIT, Epam Systems, «DevOps», «.net Programming» - Andersen-Bel, «Software Testing» - A1QA, «SAP ABAP Development», «Node.js programming» LeverX and others).

To create an educational environment aimed at ensuring the practical orientation of training, ITechArt holds a competition for the best course project for the first-year students of the Faculty of Information Technology. The leading 
specialists of IT companies are actively involved in the modernization of the curricula for specialties and curricula of special disciplines, in the formation of a line of specialties, technical tasks for course and diploma design, all types of practices, master's studies.

The students of the Faculty of Information Technologies are actively involved in the implementation of joint projects with companies (the largest: the VR-project «Virtual simulator for the training of technical personnel of gas control points» (unitary enterprise «Vitebskoblgaz») and the project «Top-level software for the gas stove verification system» (Research and production republican unitary enterprise «Belgaztekhnika»); team building in the form of a cultural and historical quest, the open championship of the Faculty of Information Technologies "IT-skills", the Republican Andersen-Bel Prize Programming Olympiad, the IT-sportland with the participation of the Andersen-Bel team, the professional conferences A1QA, Epam Systems, excursions with the participation of schoolchildren and foreign applicants in LACIT, A1QA, Epam Systems, LeverX, ITechArt, meet ups for students and schoolchildren Exadel, Corpitech, ITechArt, Andersen-Bel, etc.).

IT companies sponsor new laboratories and conferences. For example, an educational and research laboratory jointly with Epam Systems, a virtual reality laboratory jointly with Andersen-Bel and ITS Partner, an augmented reality laboratory jointly with Andersen-Bel and Corpitech, LACIT laboratory artificial neural networks. The first International Scientific and Practical Conference «Information and Communication Technologies: Achievements, Problems, Innovations (Information and Communication Technologies-2018)» (ITS Partner), First Regional IT room «POLOTSK IT-4RUM: HI TECH future of the city with a great past» (Corpitech, Faculty of Information Technology, HighTech Park) were carried out.

By creating multi-industry laboratories where students will gain knowledge in new areas and practice them, the IT business will receive staff that it is necessary now to carefully search for.

The successful, highly innovative, research and production organization LACIT proposed creating a Joint multi-industry complex on the basis of Polotsk State University.

\section{Use of information educational technologies in the formation of flexible digital skills at Polotsk State University}

As noted by Mikhail Kovalev and Galina Golovenchik «The transition to a digital economy is irreversible. There is an opinion that Belarus with its information and communication technology potential (32nd place in the world, according to ITU rating) should not hesitate. First of all, it is necessary to 
sharply increase the training of personnel for this sector of the economy - and not only programmers, but also business IT specialists, IT marketers, etc. The share of employees in the IT sector is only 2.2 percent of the employed population (estimated EY), while in the USA - 3.8 percent, the EU 3.7 percent. It is also very important to organize the effective continuous development of digital competencies among all specialists and prepare them for future changes» (Kovalev \& Golovenchik, 2018).

Following the indicated trends, in 2019, for the first time in the region, recruitment for the specialty «Electronic Marketing» took place in Polotsk State University.

The significant role of information educational technologies in the formation of flexible digital skills among specialists of various types of economic activity determines the need for their increased use. In this regard, the authors propose the creation of a web-based tool that will allow matching the labour resources of older working age with the technological parameters of jobs, as well as ensure the formation of engineering skills in children of different ages through their training in two bordering States (Latvia, Belarus).

The web tool can be placed on one of the available, simple and free platforms, for example Eliademy. It has all the necessary tools - from creating classes (using texts, video, audio, tables and other materials) to communicating with the audience. There is quite a lot of competition in the information services market, but the functionality of the designed web tool is unique in terms of coordinating the efforts of people of an older age group who want to find work, taking into account the dependence «my qualification level - the technological parameters of the workplace».

The creation of a web project will take place in stages:

- development of a business plan, including the analysis of the target audience, identifying the potential users' problems, web project monetization tools, risks;

- creation of a prototype system with the definition of high-level components of the catalogue, search, authorization, etc;

- designing mockups of the user interface and map transitions from one interface to another;

- $\quad$ description of the operation of the system for the end user;

- $\quad$ selection of software product development technology;

- $\quad$ organization of support for the operation of the resource.

Double educational diploma programmes are another educational tool that helps to build flexible skills among specialists of different types of economic activity. The authors consider the creation and ensuring the sustainable implementation of such programmes relevant in Belarus and Latvia, since 
training on them allows you:

- to form social skills of a graduate taking into account the mentality of the two countries,

- to develop process skills through testing the project method and working in cross-country team project teams,

- to develop the skills of managing the resources of two or more countries through access to the academic and infrastructure resources of another university,

- $\quad$ to receive international training and secure a competitive advantage in the labour market, not leaving the national labour market, but supplementing it with the skills and abilities that an undergraduate receives from working in intercountry educational projects,

- to improve the knowledge of a foreign language, get a European diploma, which certainly enhances the competitiveness of a specialist who studied under the double diploma programme.

An example of the practical implementation of this approach is the master's programme «Regional Planning and Development», implemented jointly with Rezekne Academy of Technologies (Latvia).

The joint curriculum of the master's programme consists of several parts:

- a national component;

- a component of a higher education institution, including the module "Disciplines of specialization”, such as Knowledge Management, Research and Analysis; Structured Dialogue between Decision Makers and Society; Regional Economics and Policy; Processes of European Integration; Intercultural Business Communications; History of Interregional Contacts (Culture Aspects); Planning, Management and Analysis of Development Projects; Spatial Planning; Transport and infrastructure Planning.

- $\quad$ compulsory courses conducted jointly by partner universities, within Module disciplines: Regional Economics and Management / Regional Socio-cultural Processes. This block involves the academic mobility of undergraduates in a partner university;

- elective courses;

- master's thesis. The Commission for the defence of the master's thesis includes teachers from the partner universities.

Thus, the authors believe that the formation of flexible skills should be carried out at all levels of higher education and can provide the formation of IT skills; improving knowledge of a foreign language; communication skills etc. 
Mietule et al., 2020. Trends in the Training of IT Specialists: Experience of Interuniversity Cooperation

\section{Conclusions}

1. The qualification of workers is one of the main factors determining the situation in the labour market. At the same time, the principle of building up cross-functional skills at the first stage of higher education, and then the deep specialization of the workforce throughout life, is not fully implemented. National labour markets show a different demand for labour across specialties. Despite the fact that in Belarus the non-technical education profile is predominant in the graduation of specialists, specialists in the field of IT technologies are more in demand. In Western countries and Belarus, there is an active process of digitalization of the economy. As a result, the need for specialists is growing.

2. The experience of the Faculty of Information Technologies of Polotsk State University includes such training elements as: conducting specialized free courses by IT companies; holding by companies of competitions for the best course project for the first-year students of the FIT, joint development of curricula for specialties and curricula of special disciplines, student participation in joint projects and activities with enterprises; team building in the form of a cultural-historical quest, conducting an open championship of the Faculty of Information technologies "IT-skills", as well as a republican programming Olympiad, excursions with the participation of schoolchildren and foreign applicants.

3. The formation of flexible skills among students and graduates, as well as the effective continuous development of digital competencies among students, is important. In the framework of this area, the authors proposed the creation of a web-based tool that allows you to combine the labour resources of older working age and people over working age with the technological parameters of jobs, as well as ensure the formation of engineering skills in children of different ages through training in Latvia and Belarus.

4. The effectiveness of the implementation of joint master's programmes in English is grounded on the example of the Regional Planning and Development Programme (university partner - Rezekne Academy of Technologies) and their role in the formation of graduates of such educational programmes with social skills, taking into account the mentality of the two countries; development of process skills through testing the project method and working in cross-country team project teams; the formation of the resource management skill of two or more countries through access to the academic and infrastructural resources of European universities. 


\section{Acknowledgements}

The paper was supported by the National Research Programme "Latvian Heritage And Future Challenges For The Sustainability Of The State" Project "Challenges For The Latvian State And Society And The Solutions In International Context (Interframe-Lv)”

\section{References}

All-Russian Center for the Study of Public Opinion. (2019). Retrieved from https://wciom.ru/index.php?id=236\&uid=9808

Avdeeva, E., \& Chaplygina, U. (2017). Features of the development of small and mediumsized businesses in the information environment. Scientific and methodological electronic journal “Concept”, S13. Retrieved from http://e-kon-cept.ru/2017/ 470166.htm/

Global Risks Report. (2017). Retrieved from http://reports.weforum.org

Kovalev, M., \& Golovenchik, G. (2018). Digital economy is a chance for Belarus. Minsk: Belarusian State University Publishing Center.

National Statistical Committee of the Republic of Belarus. (2019). Retrieved from https://www.belstat.gov.by/

Sixth European Working Conditions Survey - Overview report. (2016). Luxembourg: Publications Office of the European Union. Retrieved from https://digitalcommons.ilr. cornell.edu/cgi/viewcontent.cgi?article=1605\&context=intl

The global human capital report. (2017). Retrieved from http://www.iberglobal.com/

Zaitseva, N. (2016). The influence of the potential of Internet technologies on the development of small and medium-sized businesses, households in the information economy. Scientific electronic library Elibrary.ru, 3(29), 56-61. Retrieved from https://elibrary.ru/item.asp?id=27124627/

Ziankova, I. (2019). Some aspects of the conceptual framework for the development of a rational structure of employment in the labor market: national and world experience. Scientific and practical journal «Consumer Cooperation, 4(67), 17-25. 